\title{
The destruction of the golden calf (Ex 32:20): A materials science perspective
}

\begin{tabular}{|c|c|}
\hline \multicolumn{2}{|c|}{$\begin{array}{l}\text { Authors: } \\
\text { Tarcicio Gaitán Briceño }{ }^{1} \\
\text { Emigdio Mendoza Fandiño } \\
\text { Piedad Gañán Rojo }{ }^{3} \text { (D) }\end{array}$} \\
\hline \multicolumn{2}{|c|}{$\begin{array}{l}\text { Affiliations: } \\
{ }^{1} \text { School of Philosophy, } \\
\text { Theology and Humanit } \\
\text { Faculty of Theology, } \\
\text { Universidad Pontificia } \\
\text { Bolivariana, Medellín, } \\
\text { Colombia }\end{array}$} \\
\hline $\begin{array}{l}{ }^{2} \text { School of Eng } \\
\text { Faculty of Me } \\
\text { Engineering, } 1 \\
\text { Pontificia Boli } \\
\text { Medellín, Colc }\end{array}$ & $\begin{array}{l}\text { ineering, } \\
\text { hanical } \\
\text { niversidad } \\
\text { lariana, } \\
\text { mbia }\end{array}$ \\
\hline \multicolumn{2}{|c|}{$\begin{array}{l}{ }^{3} \text { School of Engineering, } \\
\text { Faculty of Chemical } \\
\text { Engineering, Universidad } \\
\text { Pontificia Bolivariana, } \\
\text { Medellín, Colombia }\end{array}$} \\
\hline \multicolumn{2}{|c|}{$\begin{array}{l}\text { Corresponding author: } \\
\text { Piedad Gañán Rojo, } \\
\text { piedad.ganan@upb.edu.co }\end{array}$} \\
\hline \multicolumn{2}{|c|}{$\begin{array}{l}\text { Dates: } \\
\text { Received: } 14 \text { Oct. } 2020 \\
\text { Accepted: } 01 \text { Mar. } 2021 \\
\text { Published: } 20 \text { Apr. } 2021\end{array}$} \\
\hline \multicolumn{2}{|c|}{$\begin{array}{l}\text { How to cite this article: } \\
\text { Gaitán Briceño, T., Mendoza } \\
\text { Fandiño, E. \& Gañán Rojo, P., } \\
2021, \text { 'The destruction of } \\
\text { the golden calf (Ex 32:20): } \\
\text { A materials science } \\
\text { perspective', Verbum et } \\
\text { Ecclesia 42(1), a2175. } \\
\text { https://doi.org/10.4102/ } \\
\text { ve.v42i1.2175 }\end{array}$} \\
\hline \multicolumn{2}{|c|}{$\begin{array}{l}\text { Copyright: } \\
\text { C 2021. The Authors. } \\
\text { Licensee: AOSIS. This work } \\
\text { is licensed under the } \\
\text { Creative Commons } \\
\text { Attribution License. }\end{array}$} \\
\hline \multicolumn{2}{|l|}{ Read online: } \\
\hline 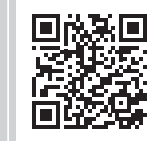 & $\begin{array}{l}\text { Scan this QR } \\
\text { code with your } \\
\text { smart phone or } \\
\text { mobile device } \\
\text { to read online. }\end{array}$ \\
\hline
\end{tabular}

One of the most fascinating and heavily debated episodes involving gold in the Old Testament is the destruction of the golden calf described in Exodus 32:20. This study considers, for the first time, this episode from a materials science perspective. Textual analysis and experimental results indicate that it is plausible to make a gold mixture fit for later human consumption by using the three steps described in the passage. The results thus suggest that Exodus 32:20 could be an ancient reference to the most commented-upon materials processes of our day: reduce the size of matter through a top-down approach.

Intradisciplinary and/or interdisciplinary implications: This article brings for the first time an approach between theological analysis and a support by materials sciences to evaluate the technical viability of the destruction of the golden calf described in Exodus 32:20. It impacts the obtained results and indicates the appropriate use of technical aspects of the writers of this text.

Keywords: exodus; golden calf; grinding; materials science; top-down approach.

\section{Introduction}

The story of the golden calf described in Exodus 32 represents, for several reasons, one of the most scrutinised episodes of the Israelites' march through the desert (Albayrak 2001; Smolar \& Aberbach 1968). Even before Julius Wellhausen's theories in the 19th century, several scholars analysed the potential incongruities of Exodus 32. Some of their objections suggest that the text is a compilation from different sources (Lin 2010). The technical details of the passage, which are essential to its overall meaning and effect, play a role in this discussion, especially when an exegetical analysis is applied to Moses' actions (Coats 1987). One of the last studies that endeavoured to address these technical details is a 1994 work of David Frankel's published in Vetus Testamentum (1994). Frankel provided a compelling description of and commentary on those previous publications concerning the destruction of the golden calf and proposed a new approach based on a textual analysis that includes alteration on the order of the steps involved in the golden calf destruction.

The investigations in the last decades on the composition of the Pentateuch reveal the enormous difficulties to date the stories composing it. Although it incorporates very old materials, the final redaction may come from the Persian period (fifth century BC) (Ska 1998:245-258). On the contrary, the literary contacts between I Kings 12:28 and Exodus 32:4 lead to the conclusion that Exodus 32 'is a polemic against Jeroboam's policy, etiologically projected in the Mosaic period' (Childs 2003:535). Now, as the religious schism caused by Jeroboam (I Ki 12:26-33) occurred in 931-930 BC, we must think that the work with gold, specifically the processes of modelling, ignition and grinding, narrated in Exodus 32:4.20 was already known to the Israelites in the 10th century. Thus, although the account is dated from a later time, the practice to which it refers is much older.

In the description of the fabrication and destruction of the golden calf, it is possible to identify three steps, which have been listed in Figure 1. The process begins with the fact that the Israelites had brought a sufficient amount of gold to make the golden calf (Ex 32:2-3) and ends with Moses making the Israelites drink the mixture of gold powder and water (which we refer to as the gold mixture; Ex 32:20). Frankel (1994:333) suggests that the preparation of the mixture is related more of an ordeal to test the people than primarily aimed at the destruction of the calf. In this regard, Frankel inclines to avoid one of the most common comparisons of the golden calf's destruction: The destruction of the Mot by Anat. This episode is narrated in Ugaritic literature; part of the variation with respect to the golden calf destruction is related to the last step when the rest of the Mot was strewn in the fields (Fensham 1966:192). 


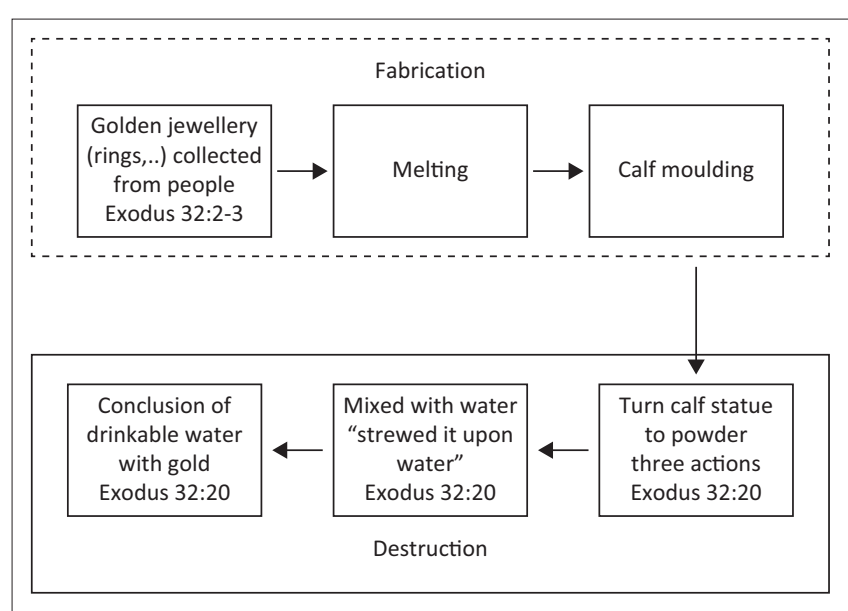

FIGURE 1: Fabrication and destruction of the golden calf based on Exodus $32: 2-3$ and $32: 20$.

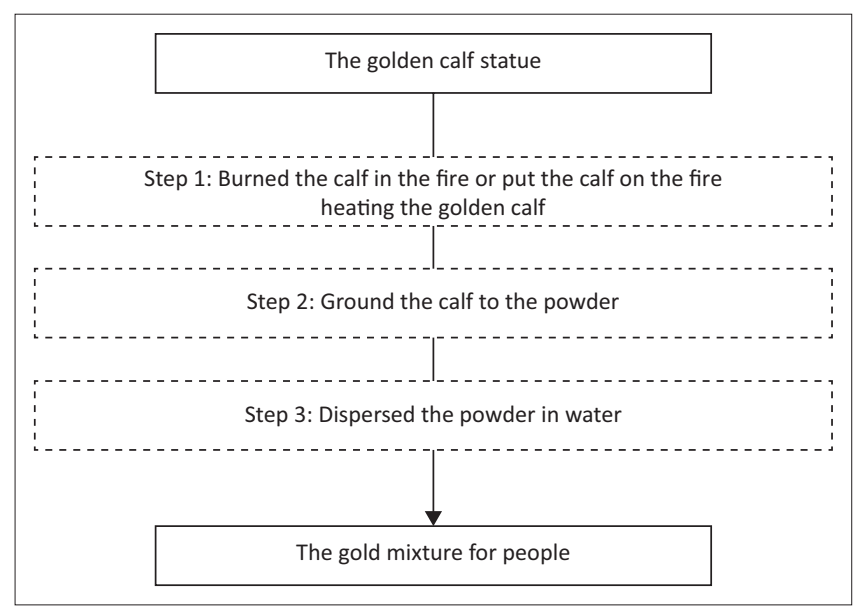

FIGURE 2: Three steps involved in the destruction of the golden calf, based on Exodus 32:20.

As Figure 2 shows, there were three steps in the destruction of the golden calf. Interpreters of the passage are confronted with the difficulty of explaining how Moses concocted the gold mixture in the desert conditions in which they found themselves. Frankel, for example, based on the difficulties described in the sequences between the golden calf passages, as in Exodus 32.19, suggests that the shattered pieces of the stone tablets were used to make the powder, which was added to the water, rather than that any part of the golden calf had been burned (Frankel 1994:338). However, if the intention of the text was to straightforwardly report the events of the episode, then the accuracy of the technical information is relevant (Edery 1994). If Exodus 32 is considered primarily a theological and moral narrative, then later exegetes needed to develop a more realistic retelling of the episode, based on wellknown or traditional facts. This is because unreliable technical data can distract the audience and cause mistrust over an entire discourse, and so soundly presented technical aspects enhance the feasibility of the whole text. For instance, non-viable technical aspects would affect the reception of the text by those who had experience with metal work, mainly because part of the listeners through the time have been experienced in metallurgy or the making of jewellery.

Currently, dialogue between different disciplines is supplying new readings or interpretations for ancient technologies and cultural practices (Vidale \& Micheli 2017:390). In one such confluence of disciplines, this study brings materials science to bear on the destruction of the golden calf to offer a new reading of Exodus 32:20, namely that the text as originally conceived by the author(s) is more realistic than the many later corrections and interpretations of the passage. In addition, an exploration of the order of the steps described in Exodus 32:20 might represent an ancient literary reference to metal fabrication. Based on archaeological evidence mentioned by Altman (1979:75), the Israelites, who existed as a recognisable culture beginning around $1500 \mathrm{BC}$, worked with gold, and gold ingots have been found in excavations in Gezer, which means that gold was known to the Israelites centuries before Exodus was written.

As far as the authors know, this work is the first contribution to the analysis of the destruction of the golden calf that combines textual analysis and experimental evaluation following the order mentioned in Exodus 32.20. Before the analysis of each step, it is first necessary to consider passages in the Hebrew Bible where gold is mentioned, and to identify what contact the people of ancient Palestine had with metallurgic technologies before or during the events behind the narratives of I Kings 12 and Exodus 32. Then, each step and their precise order as described in Exodus 32:20 (see Figure 2) can be explored analytically and experimentally, with the aim of establishing their technical viability.

This episode could then help present the Bible as a new source and inspiration to new generations, looking for more readily available and cleaner production of materials or even nanomaterials, a top-down approach (reducing the size to micro- and nano-scale) by using one of the most ancient and singular of techniques: grinding.

\section{Materials and methods}

To establish if the three steps described in Exodus 32:20 and the order adopted are plausible, in this work, two types of analyses are applied: textual and experimental. One of the premises of this work is that the Israelites in this period knew how to work with metals such as gold. This idea is explored through a review of the principal scientific and technical influences on the Israelites, especially that of ancient Egypt. The metallurgical and material processing of gold was carried out by using ancient Egypt technologies that had a strong influence on the events related in Exodus.

The textual analysis presented here focusses on key verbs stated in Exodus 32:20, looking to reveal the underlying ideological and cultural assumptions on the Bible. This analysis helps us develop the experiment conducted subsequently. The following subsections describe the experimental materials, process and testing. 


\section{Materials}

One of the central parts of the debate about the destruction of the golden calf is related to the order of the three steps of the process (see Figure 2), and mainly the second step, the grinding of the gold, which is the part that has been considered unrealistic (Fensham 1966:191; Frankel 1994:330-331; Loewenstamm 1967:481-482; Noth 1962). To gather experimental information on the plausibility of these steps, a sample of gold was treated following the approach extracted from Exodus 32:20. The sample gold corresponds to 18-karat recycled gold jewellery supplied by a local goldsmith. This type of gold source was chosen to reflect the idea that the golden calf was made by using gold items provided by the Israelites, as mentioned in Exodus 32:2. The gold alloy composition of these pieces of jewellery was 75 wt.\% gold, $11 \mathrm{wt} . \%$ copper and $14 \mathrm{wt} . \%$ silver. To simulate the way the golden calf was burned in the Old Testament, the pieces were heated over wood logs approximately $400 \mathrm{~mm}$ in length, with a random wood-to-gold ratio of approximately 17:1.

\section{Processing}

See Figure 2 for an outline of the three steps of this process. In the first step (heating the golden calf), the recycled jewellery was combined with the wood in an open, traditional ceramic crucible used by goldsmiths. The crucible was heated to a temperature of $900^{\circ} \mathrm{C}$. This temperature was chosen based on ancient Egyptian gold refining (Notton 1974:56). The remelted sample rested in the ceramic crucible until it reached room temperature. In the second step, to simulate the manual grinding process, two rough stones chosen at random served as a rudimentary mill. During grinding, the remelted samples were compressed and rubbed between the rough stones, simulating a common ancient process of grinding. The resulting powder located on the stones was collected by washing it off the stones using drinking water. This collection process was the third step. Before grinding, the stones were cleaned by using detergent and antibacterial soap to remove impurities that, potentially, could interfere with the evaluation of the gold mixture. The cleaned stones used for the grinding were thus free of the presence of gold, copper and silver.

\section{Testing}

After heating, the remelted samples were observed by using optical evaluation to detect the presence of defects such as voids as crypts and gaps and impurities generated by the thermal process in a non-controlled atmosphere. For this propose a stereomicroscope, Nikon SMZ745T, was used. As a result of the size of the golden alloy samples, zoom magnification was set at $2 \times$.

The powder produced by the manual grinding was confirmed to contain several substances removed from the stones and the remelted sample. To establish the presence of the gold in the water mixture, five drops of the supernatant of the powder mixture were analysed by using a scanning electron microscope (SEM) with Energy Dispersive Spectroscopy
(EDS) (JCM-6000 Plus NeoScope). Before the SEM test, drops of $30 \mu \mathrm{l} / \mathrm{L}$ were placed on an aluminium support and dried at room temperature for $24 \mathrm{~h}$. After this period, the samples were tested.

\section{Ethical considerations}

This article followed all ethical standards for research without direct contact with human or animal subjects.

\section{Results and discussion}

As mentioned here, prior to evaluating whether the three steps described in Exodus 32:20 were plausible as written, it was necessary to provide archaeological facts to support the connection between the peoples of ancient Palestine and the metallurgic capacities of that time.

\section{Metallurgy at the time of proposed events mentioned in Exodus}

The Old Testament includes more than 380 references to gold. Exodus 3:22, for example, indicates that Israelites possessed enough gold before the elaboration of the golden calf. There are references to gold exploitation or gold ore in Havilah (Gn 2:11-12), Ophir (1 Ki 10:11) and Arabia (1 Ki 10:14-15). Explicit details regarding the construction and gilding of the Ark of the Covenant are described in Exodus 25:11-13. The authors of the Pentateuch would have been broadly familiar with how gold was obtained and the several alternatives for its conformation. These techniques include, for example, the moulding by casting, cold works that involve the deformation on multiple slip planes during the metal conformation and gilding methods useful for the gilding of metallic or non-metallic supports; that is, the case the passage Exodus 36:34 that relates that Israelite craftsmen gilded objects 'overlaid the boards with gold'. ${ }^{1}$ In addition, there are several references to work using hammers: 'And thou shalt make two cherubims of gold, of beaten work shalt thou make them' (Ex 25:18); 'And he made two cherubim of gold, beaten out of one piece made he them' (Ex 37:7); and 'And they did beat the gold into thin plates' (Ex 39:3). All these passages describe conventional technical processes that, even now, are used by goldsmiths.

\section{Gold processing and Egyptian influence}

References to the connections between Israelites and Egyptians before Exodus 32:20 are mentioned in the Old Testament, in different parts of Genesis and in previous passages in Exodus. The influence of Ancient Egyptian culture can be associated with the considerable time that Israelites spent under Egyptian rulers including Amarna period (Younger 1990); several authors mention these contacts (Bailey 1971:102; Reichert 1973; Younger 1990). One of these authors is Bailey (1971:102) who indicated that Israel was in touch with Egyptian people before the Exodus and since the exile, in episodes such as that of Jeroboam in the court of Shishak 1.All texts quoted from the Old Testament are from the King James Version (KJV) of the Bible. 
related in I Kings 11:40. It is essential to keep in mind that although the respective events in I Kings and Exodus took place in different periods. This situation suggests that the authors or correctors of these texts recorded information about the well-known ancient techniques of metallurgy.

It is now well known and even commented upon by authors such as Reichert (1973:31) that the Palestinian region was strongly influenced by cultures with experience at working with gold because the region was a natural transit route between Egypt and Mesopotamia. In different periods, Egyptian governors ruled the Palestinian territory. For example, in tribute documents of the 12th to 19th Egyptian dynasties, some Canaanite cities are mentioned. Other sources reported by Reichert (1973:31) that help to support connections to Egypt are inscriptions in the Temple of Thutmose III (reigned [r.] 1479-1425 BC) in Karnak, which list more than 118 cities dominated by the pharaoh, including Cana, Megiddo and Kadesh. The circulation of gold through Palestine may have also resulted from the Egyptian campaign during the reign of Thutmose III. Thutmose III brought back war booty from the kings of Megiddo and Kadesh, including 10 gilt carriages with shafts of pure gold (Klemm et al. 2001:643). Some scholars also reference two other highly significant pharaohs who are linked to the history of Palestine and gold exploitation: Seti I (r. 1290-1279 BC) and Ramesses II (r. 1279-1213 BC) (Klemm et al. 2001:645).

It is widely recognised that Egypt was one of the first civilisations to work with gold. Several objects have been excavated that date to approximately $3000 \mathrm{BC}$, reflecting the impressive accomplishments of Egyptians by that date (James 1972:38). Examples of exceptional work with gold are the gold objects, mostly gilded, found in the burial chamber of King Tutankhamun, who died in 1352 BC. Sheets of gold foil were used, and maximal thickness was obtained by layering. One of the most iconic examples of this technique is the inner sarcophagus and death mask of Tutankhamun, which contains $110 \mathrm{~kg}$ of gold (James 1972:38; Killick 2013:540).

Much of the gold used by Egyptian artisans might have been obtained from several regions in present-day Sudan (Habashi 2005:25). The Egyptians were one of the first cultures to treat gold-bearing rocks. Because water was used to isolate precious metal from quartz stones, and there were difficulties sourcing water at gold-mining centres, it is possible that the stones were transported by using donkeys to the Nile River, where gold ore processing could take place by using water. However, a method was needed to reduce the weight of the stones to improve the transportation (Ogden 1992:261). One such method was to heat the stones, hammer them and then crush them into a powder in a mortar, resulting in a load that was more manageable on the long journey to the river. This ancient process to crush the stones provides an alternative method for processing gold.

Gold was initially hammered out by using hammerstones until the hafted hammer was invented at some time in the first millennium BC (Altman 1979:75). It is possible that the
Egyptians' remarkable knowledge of processing gold exerted influence on the artisans of neighbouring lands such as Palestine. Gold artefacts of Canaanite origin dating to around 1600 to 1400 BC have been discovered in Gezer and Tell el Ajjul (Beth Agilim, near Gaza). These artefacts demonstrate that Canaanite craftsmen had the skills required to produce gold leaf and gold foil (Loyson 2011:146). In summary, interaction between Palestine people and their powerful neighbour, Egypt, supplied artisans and goldsmiths with the necessary technical skills to manipulate gold and carry out the steps involved in destroying an object as large as the golden calf.

At this point, a connection needs to be made between the kind of technical processes just mentioned and the highly precise verbs used in Exodus 32:20, with the aim of exploring whether the steps described and the order in which those steps were taken was plausible, given the technological advancements prevalent in the region at that time.

\section{Textual analysis and materials science perspective}

In this section, the steps of the process described in Exodus 32:20 will be considered one by one from the textual analysis and material science perspective.

\section{Step 1: Heating the golden calf}

According to Clines (2011:194-195), the first meaning of the verb s'rp is 'burn objects, food, animals, usually to destroy' (also Brown, Driver \& Briggs 1952:976). In the Hebrew Bible, this verb is used 125 times, whereas the noun 'éšs (fire) is used 382 times; both words are used together 80 times. The sense of the expression is to burn until consumed by burning. It also appears in texts linked to idolatry, such as in Joshua 6:24 'And they burnt the city with fire, and all that was therein'; 1 Samuel 30:

And it came to pass, when David and his men were coming to Ziklag on the third day that the Amalekites had invaded the south, and Ziklag, and smitten Ziklag, and burned it with fire. (v. 1).

and Isaiah 1:7 'Your country is desolate, your cities are burned with fire'.

Gold is one of the most recycled metals throughout human history, and the step of heating the golden calf should be understood to be a remoulding process as opposed to melting of unworked gold or during gold purification. Remelting gold objects was incontrovertibly an Egyptian practice, used to purify gold by removing its impurities; through such a process, gold of nearly 95\% purity could be produced (Loyson 2011:147). The practice is known to have been performed in the Nile Valley and even at more remote extraction sites. During the remelting process, primarily when heating occurs in an open kiln without control over atmospheric conditions, the metal can be exposed to different impurities, and additionally alteration on the crystallisation of metal can take place (Ott \& Raub 1985:140). After heating, as the metal returns to room temperature, several defects 


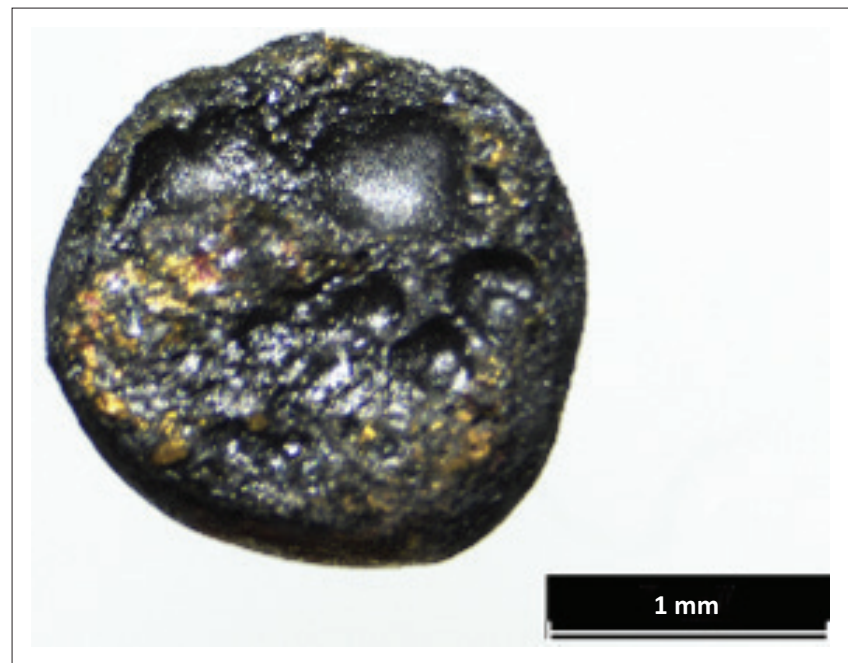

Source: Micrograph obtained using the information of the stereomicroscope, Nikon SMZ745T, published with permission from Piedad Gañán Rojo.

FIGURE 3: Sample of gold with defects.

such as voids and variations in the structure of the metal are frequently observed (Ott \& Raub 1985:140). Such defects affect the mechanical behaviour of the metal (Ott \& Raub 1985:140) and reduce the challenges to the plausibility of the next step in the destruction of the golden calf. Figure 3 shows a remelted sample of recycled gold jewellery that has been heated in an open crucible and then cooled according to the procedure described here in the materials and method section. The sample reflects an evident presence of carbonaceous material from the wood added to the process used to heat the calf. Voids found had lengths that varied between $0.1 \mathrm{~mm}$ and $0.5 \mathrm{~mm}$; these defects formed during the solidification of the sample. The origin of the voids can be linked to gas entrapment; part of the gas corresponds to products of the degradation of the wood during remelting that cannot escape to the atmosphere. The difference in the forms and sizes of these pores comes from the heating of metal in a non-controlled atmosphere and the absence of elements such as a counter-mould to apply compression during the cooling time.

\section{Step 2: Grinding into powder}

This step is also suggested in a passage from Deuteronomy 9:21:

And I took your sin, the calf which ye had made, and burnt it with fire, and stamped it, and ground it very small, even until it was as small as dust.

As mentioned in the introduction, some scholars, such as Frankel, have challenged the plausibility of reducing gold to powder (Frankel 1994:330). Was such a feat even possible by using the technology available at the time?

The term used in reference to grinding the golden calf, $t h n$, is unusual in the Hebrew Bible, being used only seven times: Exodus 32:20, Deuteronomy 9:21, Numbers 11:8 ('And the people went about, and gathered it, and ground it in mills'), Judges 16:21 (describing the Philistines forcing Samson to grind), Job 31:10 and Isaiah 3:15 and 47:2 ('Take the millstones, and grind meal'). In all cases, 'grind' means to reduce to small particles or powder by crushing. ${ }^{2}$

Grinding with a mill does not require very sophisticated tools, but only a slab or flat, hard rock and a runner stone. However, by using this technology it is possible to obtain new structures, even nanostructures by the top-down approach through progressive disintegration of the solids (Baláž et al. 2013:7599). Mills were commonly and widely used throughout the ancient world. Some ancient mills consisted of two circular stones of about $60 \mathrm{~cm}$ in diameter (Klemm et al. 2001:655). The bottom stone had a convex face that fitted with the concavity of the rotating top stone. Even now, similar systems are used in the low-cost mining industry for metal and nonmetal minerals, in goldsmithing and in the production of flour and different types of traditional meals (Cappelli, Oliva \& Cini 2020:147).

This ancient method of grinding produced fine gold powder. According to Pimpang et al. (2008:251), with a manual grinding method it is possible to obtain gold nanoparticles with diameters of only $150 \mathrm{~nm}^{3}$; when this powder is dispersed into water, the colloidal solution turns blue and might even be drinkable when the size of the particles is imperceptible to the naked eye. ${ }^{4}$ Other authors report that grinding at room temperature can reduce the thickness of the gold foil from $50 \mathrm{~mm}$ to $100 \mathrm{~nm}$ to between 250 and 500 atoms in thickness (Nutting \& Nuttall 1977:3).

As the text does not mention additional steps between the grinding and the dispersion of the powder in the water, we can assume that the remelted gold from the golden calf was ground. Metals and metallic alloys are defined in materials science by their crystalline structures, meaning that the atoms are aligned in a regular lattice and by the presence of defects such as voids. Bulk solid metal consists of many crystals or grains, as they are commonly called, each oriented in a different direction (Corti 1999:41). The size and structure of these grains are amongst factors affecting the solidification of metal during the cooling process and affect the solid's mechanical properties (Ott \& Raub 1981:69). In the remelted sample that simulated the golden calf, the progressive disintegration of the solid during the grinding process was facilitated by the solid's defects generated during the cooling process. These defects included the modification of the grain structure, the presence of impurities such as non-gold components in the remelted mass after firing (e.g. carbonaceous material, observed in Figure 3 ) and the presence of voids commented on here.

\section{Step 3: Mixing the powder in water}

After the remelted sample was ground by using a rudimentary mill, as described in the material and methods section, a 2.https://en.oxforddictionaries.com/definition/grind (Accessed: February 1, 2019).

3.In the International System of Units (SI), $1 \mathrm{~nm}$ equals 1 nanometer. One-billionth of a metre.

4.It is just possible to see powder at the nanometric level by using a high-resolution microscope, such as an atomic force microscope (AFM). The magnification capacity of this microscope is around $100000 \times$. 


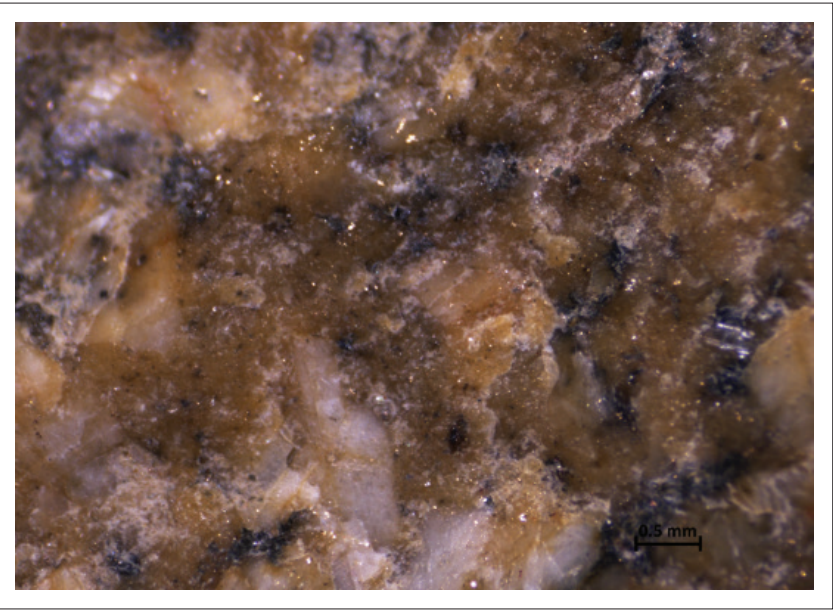

Source: Micrograph obtained using the information of the stereomicroscope, Nikon SMZ745T, published with permission from Piedad Gañán Rojo.

FIGURE 4: Micrograph of the surface of the rudimentary mill after cleaning with potable water at a magnification of $2 x$.

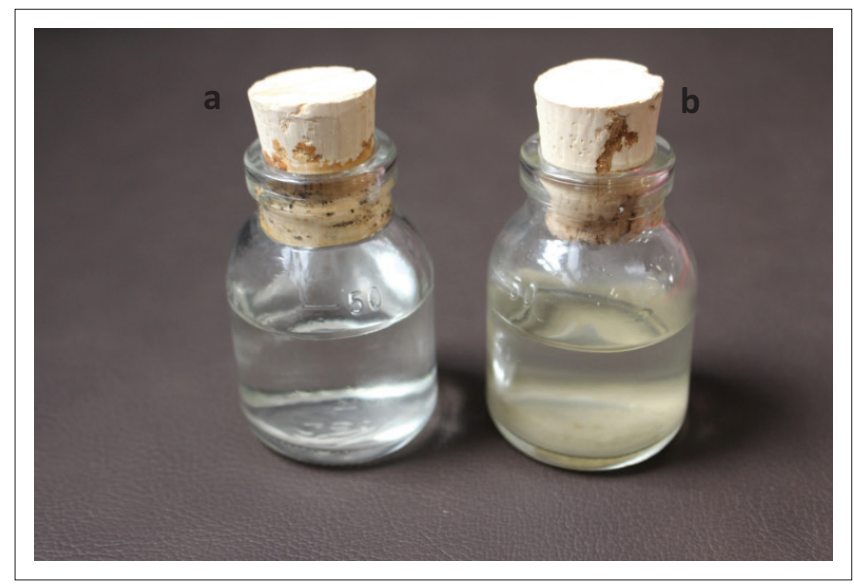

Source: Photograph taken by Piedad Gañán Rojo, published with permission from Piedad Gañán Rojo.

FIGURE 5: (a) Clean water (b) Powder mixture.

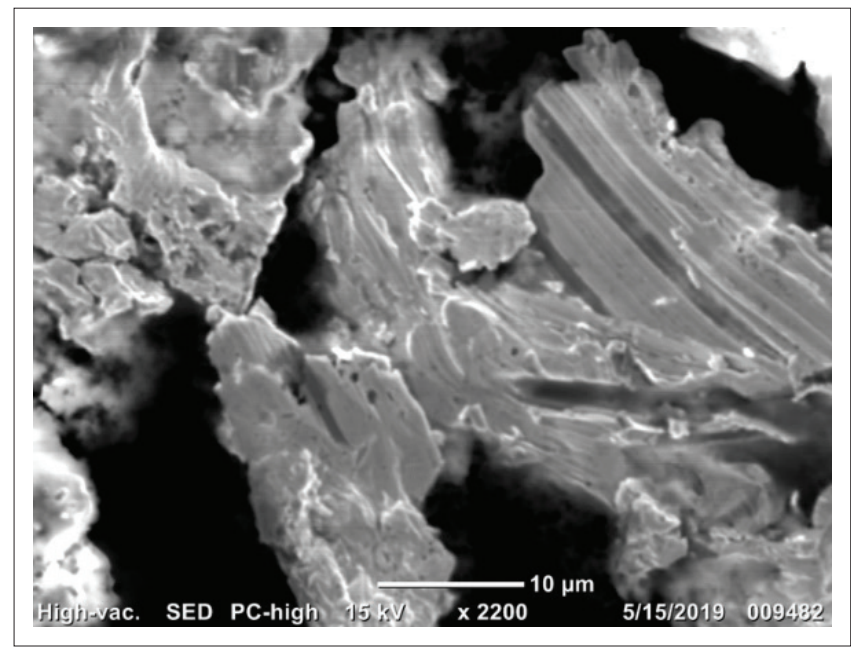

Source: Micrograph obtained using SEM microscope, published with permission from Piedad Gañán Rojo.

FIGURE 6: Scanning electron microscope image of particles present in the supernatant liquid of the gold mixture.

yellow-golden powder was successfully obtained from the stones by using freshwater, producing the gold mixture. The colour of the gold mixture suggests that the size of the golden particles is larger than $160 \mathrm{~nm}$. Figure 4 shows the dried surface of one of the stones after cleaning with freshwater. Small and randomly distributed, brilliant particles are observed, maybe corresponding to gold particles that are remaining on the stone after the cleaning process.

Figure 5 shows the photographs of the clean water before mixing with the obtained powder (Figure 5a) and the resulting powder mixture that contains gold (Figure 5b). Both photographs were taken 4 weeks after the preparation of the mixture. In Figure 5b, the presence of both sediment and supernatant parts is conspicuous.

The supernatant liquid of the powder mixture looks transparent to the naked eye, like -coloured water. Figure 6 shows an SEM image of the particles found in drops of this supernatant liquid. These particles, as indicated in Figure 6, have lengths in the order of 20 microns; however, they remain dispersed in the liquid even after several weeks.

The presence of the gold on the powder mixture is suggested by the yellow colour of the mixture; however, the EDS results of the drops extracted from the supernatant indicate that the gold content on each drop was between $70 \mathrm{wt} . \%$ and $85 \mathrm{wt} . \%$. These results confirm that the mixture effectively contains the gold drawn from the remelted sample that simulates the golden calf, and hence that by following the three steps described in Exodus 32:20 it is possible to obtain such a golden mixture.

The successful preparation of a stable powder mixture with the presence of gold indicates that Exodus 32:20 contains clear instructions for a top-down material-processing approach, by using low-cost equipment and minimal consumption of energy. Both these aspects suggest that this passage summarises a fabrication technique compatible with the emerging principles of green engineering that is possible to use at industrial scale. ${ }^{5}$

The EDS results also indicate the presence of nonmetallic elements such as calcium or potassium related to the chemical composition of the stones. However, their presence should not complicate the applicability of the process, as the water Moses used was also in contact with stones with comparable chemical composition; similarly, in the ordeal ritual of the bitter water mentioned in Numbers 5:17, the water prepared is made with 'dust that is in the floor of the tabernacle', dust that could contain similar nonmetallic elements as in our simulated experiment.

With respect to the gold in the mixture, current research does not indicate that the human ingestion of gold particles at the micron level dispersed in a liquid would cause any harm (Cabuzu et al. 2015:1605). Furthermore, several researchers have evaluated the use of such liquids for medical application (Cabuzu et al. 2015:1605). The upshot seems to be that the mixture could be consumed without toxicological problems 5.Green engineering includes several routes to design, produce and commercialise
products by efficient energy consumption, reducing human health risk and low generation of residues. 
and thus could have fulfilled its purpose as a teaching tool for the Israelites.

\section{Conclusion}

This work presents for the first time the successful production of a golden mixture following Exodus 32:20, corresponding to the product of the destruction of the calf, as described heating the golden calf, grinding it and dispersing the powder in water. To achieve this goal, the textual analysis was essential to orient the experiment, and this stands as clear evidence of the importance of interdisciplinary work to achieve a better understanding of different events, such as, in this case, the destruction of the golden calf.

The results support the idea that the literal sense of the passage can be supported by the technical knowledge of the writers, the original audience or later exegetes, yielding a realist interpretation of this crucial text. The theological and moral implications of the story can be offered and explored without concern for its technical aspects.

According to these results, Exodus 32:20 can be identified as the ancient texts providing evidence of and information on material fabrication by using the top-down approach by grinding. The low cost of the equipment required to develop the process and its low energy consumption make this passage relevant text to green engineering at the present time.

\section{Acknowledgements}

The authors would like to thank Carlos Rene Muñoz Jiménez for his care and attention to sample preparation.

\section{Competing interests}

The authors declare that they have no financial or personal relationships that may have inappropriately influenced them in writing this article.

\section{Authors' contributions}

T.G.B., E.M.F. and P.G.R. carried out activities related to: conceptualisation, methodology design, formal analysis, investigation, validation activities, review and editing final version. T.G.B. and P.G.R. carried out the writing of original drafts. P.G.R. carried out the project administration and the funding acquisition. All authors read, improved and approved the final manuscript.

\section{Funding information}

This original research was made possible through the support of the Research Centre of Universidad Pontificia Bolivariana Medellín-Colombia, but not through a specific grant.

\section{Data availability}

The authors confirm that the data supporting the findings of this study are available within the manuscript.

\section{Disclaimer}

The views and opinions expressed in this article are those of the authors and do not necessarily reflect the official policy or position of any affiliated agency of the author.

\section{References}

Albayrak, I., 2001, 'The qur'anic narratives of the golden calf episode', Journal of Qur'anic Studies 3(1), 47-69. https://doi.org/10.3366/jqs.2001.3.1.47

Altman, J., 1979, 'Gold in ancient Palestine: Methods of fabrication in successive cultures', Gold Bulletin 12(2), 75-82. https://doi.org/10.1007/BF03216544

Bailey, L.R., 1971, 'The golden calf', Hebrew Union College Annual 42(1), 97-115, viewed 01 September 2020, from https://www.jstor.org/stable/23506717.

Baláž, P., Achimovičová, M., Baláž, M., Billik, P., Cherkezova-Zheleva, Z., Criado, J.M. et al., 2013, 'Hallmarks of mechanochemistry: From nanoparticles to technology', Chemical Society Reviews 42(18), 7571-7637. https://doi.org/10.1039/c3cs35468g

Brown, F., Driver, S. \& Briggs, C., 1952, A Hebrew and English lexicon of the Old Testament, Clarendon Press, Oxford.

Cabuzu, D., Cirja, A., Puiu, R. \& Grumezescu, A.M., 2015, 'Biomedical applications of gold nanoparticles', Current Topics in Medicinal Chemistry 15(16), 1605-1613. https://doi.org/10.2174/1568026615666150414144750

Cappelli, A., Oliva, N. \& Cini, E., 2020, 'Stone milling versus roller milling: A systematic review of the effects on wheat flour quality, dough rheology, and bread characteristics', Trends in Food Science \& Technology 97(1), 147-155. https://doi. org $/ 10.1016 / j$.tifs.2020.01.008

Childs, B., 2003, El libro del Éxodo, Verbo Divino, Navarra.

Clines, D. (ed.), 2011, The dictionary of classical Hebrew, vol. 8, Sheffield Phoenix Press, Sheffield.

Coats, G.W., 1987, 'The golden calf in psalm 22', Horizons in Biblical Theology 9(1), 1-12. https://doi.org/10.1163/187122087X00022

Corti, C.W., 1999, 'Metallurgy of microalloyed 24 carat golds', Gold Bulletin 32(2), 39-47. https://doi.org/10.1007/BF03214789

Edery, M., 1994, Libro del Éxodo, Editorial Sinai, Tel Aviv.

Fensham, F.C., 1966, 'The burning of the golden calf and Ugarit', Israel Exploration Journal 16(3), 191-193, viewed 01 September 2020, from https://www.jstor.org/ stable/27925060.

Frankel, D., 1994, 'The destruction of the golden calf: A new solution', Vetus Testamentum 44(3), 330-339. https://doi.org/10.1163/156853394X00330

Habashi, F., 2005, 'Gold-an historical introduction. Developments in mineral processing', in M. Adams (ed.), Advances in gold ore processing, pp. 25-48, Elsevier, London.

James, T.G.H., 1972, 'Gold technology in ancient Egypt', Gold Bulletin 5(2), 38-42. https://doi.org/10.1007/BF03215160

Killick, D., 2013, 'Gold and gold mining in ancient Egypt and Nubia', Azania: Archaeological Research in Africa 48(4) 539-541. https://doi.org/10.1080/0067270X.2013.852381

Klemm, D., Klemm, R. \& Murr, A., 2001, 'Gold of the pharaohs $-6,000$ years of gold mining in Egypt and Nubia', Journal of African Earth Sciences 33(3-4), 643-659. https://doi.org/10.1016/S0899-5362(01)00094-X

Lin, T.-Y., 2010, The golden calf, god's nature, and true worship in Exodus 32-34, Trinity International University, Deerfield, IL.

Loewenstamm, S.E., 1967, 'The making and destruction of the golden calf', Biblica 48(4), 481-490.

Loyson, P., 2011, 'Chemistry in the time of the pharaohs', Journal of Chemical Education 88(2), 146-150. https://doi.org/10.1021/ed100492a

Noth, M., 1962, Exodus, a commentary (Old Testament Library), SCM Press, London.

Notton, J.H.F., 1974, 'Ancient Egyptian gold refining: A reproduction of early techniques', Gold Bulletin 7(2), 50-56. https://doi.org/10.1007/978-94-015-1292-3_16

Nutting, J. \& Nuttall, J.L., 1977, 'The malleability of gold: An explanation of its unique mode of deformation', Gold Bulletin 10(1), 2-8. https://doi.org/10.1007/BF03216517

Ogden, J., 1992, 'Gold in antiquity', Interdisciplinary Science Reviews 17(3), 21-270. https://doi.org/10.1179/030801892791925475

Ott, D. \& Raub, C.J., 1981, 'Grain size of gold and gold alloys', Gold Bulletin 14(2), 69-74. https://doi.org/10.1007/BF03214600

Ott, D. \& Raub, C.J., 1985, 'Investment casting of gold jewelry', Gold Bulletin 18(4), 140-143. https://doi.org/10.1007/BF03214696

Pimpang, P., Sutham, W., Mangkorntong, N., Mangkorntong, P. \& Supab, C., 2008, 'Effect of stabilizer on preparation of silver and gold nanoparticle using grinding method', Chiang Mai Journal of Science 35(2), 250-257.

Reichert, R., 1973, Historia de Palestina: Desde los primeros tiempos hasta nuestros días, Herder, Barcelona.

Ska, J.L., 1998, Introduzione alla lettura del Pentateuco, Dehoniane, Roma.

Smolar, L. \& Aberbach, M., 1968, 'The golden calf episode in postbiblical literature', Hebrew Union College Annual 39(1), 91-116. https://www.jstor.org/stable/i23502923

Vidale, M. \& Micheli, R., 2017, 'Protohistoric graveyards of the swat valley, Pakistan New light on funerary practices and absolute chronology', Antiquity 91(356) 389-405. https://doi.org/10.15184/aqy.2017.23

Younger, K.L., 1990, Ancient conquest accounts: A study in ancient near Eastern and Biblical history writing, Sheffield Academic Press, Sheffield. 